\title{
IDENTIFICAÇÃO BOTÂNICA E ANATOMIA DA MADEIRA DE DISCARIA AMERICANA GILLIES ET HOOKER ${ }^{1}$
}

\author{
SIDINEI RODRIGUES DOS SANTOS ${ }^{2}$ JOSÉNEWTONCARDOSO MARCHIORI $^{3}$ \\ THAIS SCOTTIDO CANTO-DOROW ${ }^{4}$
}

\begin{abstract}
RESUMO
O presente trabalho trata da descrição botânica e anatomia da madeira de Discaria americana Gillies et Hooker, com base em material coletado no Estado do Rio Grande do Sul. A estrutura microscópica da madeira reúne: elementos vasculares muito curtos a curtos, com placas de perfuração simples e espessamentos espiralados na parede; traqueídeos vasculares abundantes junto a vasos com espessamentos espiralados; parênquima paratraqueal pouco abundante; raios heterogêneos com 1-4 células de largura, compostos principalmente de células quadradas mas com células eretas na margem; e fibras libriformes não septadas, extremamente curtas a muito curtas.
\end{abstract}

\section{SUMMARY}

[Botanical identification and wood anatomy of Discaria americana Gillies et Hooker].

This paper deals with the botanical description and wood anatomy of Discaria americana Gillies et Hooker, based on materials from the State of Rio Grande do Sul, Brazil. The wood microscopic structure showed: very short to short vessel elements, with simple perforation plates, helical thickenings and alternate intervessel pits; abundant vascular tracheids around vessels, also with helical thichenings on the walls; paratracheal axial parenchyma; heterocellular rays, with 1-4 cells wide, composed mostly by square cells, but with upright cells in the margins; and very short to short non-septate libriform fibers.

\section{INTRODUÇÃO}

A família Rhamnaceae compreende cerca de 58 gêneros e 900 espécies, distribuídas pelas regiões temperadas, subtropicais e tropicais do mundo (Barroso, 1984); pobremente representada na flora brasileira, ela resume-se a 8 gêneros e 9 espécies no Rio Grande do Sul, incluindo subarbustos, arbustos, árvores e lianas, que habitam áreas campestres, a orla ou estratos inferiores de florestas.

Geralmente espinescentes e de ambientes secos, as Ramnáceas brasileiras apresentam folhas simples trinervadas, pétalas côncavas, estames opostos às pétalas, ovário nitidamente médio e óvulos basais (Schultz, 1984).
O gênero Discaria Hook. compreende 8 espécies, distribuídas pela América do Sul, Oceania e Nova Zelândia (Tortosa, 1995). Tratam-se de arbustos espinhosos subáfilos ou de folhas perenes, com frutos do tipo cápsula tricoca; as flores, de cálice tubuloso (4-5-dentado) e corola nula ou com 4-5 pétalas, apresentam 4-5 estames insertos no tubo calicinal, ovário trilocular, estilete glabro, estigma trífido e disco aderido ao tálamo, de margem livre, não enrolada (Bustamante, 1976). Afim a Discaria, o gênero Colletia diferencia-se por suas flores apétalas, pelo disco floral de bordo involuto e pelos ramos com nós não demarcados, sem linha transversal (Hurrell \& Bazzano, 2003).

1 Artigo recebido em 15/01/2007 e aceito para publicação em 30/01/2007.

2 Biólogo, mestrando do Programa de Pós-Graduação em Engenharia Florestal, Centro de Ciências Rurais, Universidade Federal de Santa Maria, CEP 97105-900, Santa Maria (RS). sthurt.bio@gmail.com

3 Engenheiro Florestal, Dr., bolsista de Produtividade em Pesquisa do CNPq, Professor Titular do Departamento de Ciências Florestais, Universidade Federal de Santa Maria, CEP 97105-900, Santa Maria (RS). balduinia@mail.ufsm.br

4 Bióloga, Dra, Professora do Departamento de Biologia, Universidade Federal de Santa Maria, CEP 97105-900. thaisdorow@smail.ufsm.br 
Nativa em Santa Catarina e Rio Grande do Sul, Discaria americana Gill. et Hook. é o único representante do gênero no país, até o momento. Espécie heliófila e seletiva higrófila, habita preferencialmente ambientes úmidos e ensolarados, em margens rochosas de arroios e na orla de matas ciliares (Johnston \& Soares, 1972).

Com relação à anatomia da madeira, Metcalfe \& Chalk (1972) relacionam para a maioria da família: vasos tipicamente pequenos, comumente em múltiplos e com arranjo tendente a radial; porosidade em anel; vasos de lenho tardio com espessamentos espiralados; placas de perfuração simples; pontoações intervasculares alternas; elementos vasculares de comprimento médio a moderadamente curtos; parênquima predominantemente paratraqueal; fibras curtas ou de comprimento médio; raios marcadamente heterogêneos até homogêneos, por vezes compostos inteiramente de células quadradas a eretas; fibras com pontoações simples, de comprimento médio a moderadamente curtas; e presença de traqueídeos vasculares em espécies com vasos em arranjo diagonal ou dendrítico.

Para o gênero Discaria, Record \& Hess (1949) relacionam: porosidade em anel mais ou menos distinta; poros em arranjo ulmiforme ou zig-zag diagonal; e raios com até 6 células de largura. Para as madeiras do gênero, Metcalfe $\&$ Chalk (1972) agregam: porosidade em anel ou semi-difusa; vasos de diâmetro inferior a 100 $\mu \mathrm{m}$, em arranjo semelhante ou quase ulmiforme; parênquima paratraqueal aliforme, por vezes localmente confluente; e fibras de paredes espessas a muito espessas.

Em sua diagnose do gênero, Record (1939) inclui, entre outras características anatômicas: anéis de crescimento distintos; porosidade em anel; poros de paredes finas, muito pequenos a diminutos, não individualmente visíveis a olho nú; vasos muito numerosos e com espessamentos espiralados, agrupados em arranjo diagonal, zig-zag ou faixas concêntricas, resul- tando num padrão ulmiforme; raios de 1-6 células de largura e até mais de 50 células de altura, heterogêneos em parte; pontoações raiovasculares pequenas a médias, por vezes unilateralmente compostas; parênquima escassamente paratraqueal; e fibras de paredes espessas, com pontoações diminutas. Sobre os aspectos gerais e macroscópicos da madeira, o mesmo autor cita para Discaria: cerne castanho e alburno amarelado, não nitidamente demarcado; brilho médio; odor e gosto não característicos; madeira dura, pesada, resistente, de textura média, com grã reta a irregular, fácil de trabalhar, embora muito fibrosa, de durabilidade presumivelmente baixa, e carente de interesse comercial.

Primeira de uma série de publicações aliando descrição botânica e anatomia das madeiras de Rhamnaceae, o presente trabalho visa a contribuir para o melhor conhecimento desta família no sul do Brasil.

\section{MATERIAL E MÉTODOS}

O material estudado compreende duas amostras de madeira e exsicatas botânicas procedentes de distintos herbários do Rio Grande do Sul.

Sobre as amostras de madeira, obtidas na xiloteca do Herbário do Departamento de Ciências Florestais (HDCF) da Universidade Federal de Santa Maria, constam os seguintes registros:

- HDCF 1779. Pedras Altas, Potreiro da Capororoca; Marchiori s.n., 20.VII.1985.

- HDCF 2197. Caçapava do Sul, Pedra do Segredo; Marchiori n. 245; 14.I.1986.

As exsicatas examinadas para a descrição botânica integram os acervos do HDCF (Herbário do Departamento de Ciências Florestais, Universidade Federal de Santa Maria, RS), PEL (Herbário do Departamento de Botânica, Universidade Federal de Pelotas, RS), PACA (Herbarium Anchieta, Unisinos, São Leopoldo, RS) e SMDB (Herbário do Departamento de Biologia, Universidade Federal de Santa Maria, RS), constando os seguintes registros: 
BRASIL: RIO GRANDE DO SUL: Alegrete, estância do major Augusto Ferreira da Costa, arbusto paucifoliado, espinhoso, com flores, J. N. C. Marchiori s.n., 1.XII. 1983 (HDCF 1406); ibidem, Ibirocai, material com flores, J. N. C. Marchiori s.n., 9.IX.1984 (HDCF 1567). Bagé, BR-153, ca. de $10 \mathrm{~km}$ da ponte do rio Camaquã, em beira de estrada, frutos imaturos, com cálice persistente, verde, J. A. Jarenkow 3264, 09.XI.1996 (PEL 16.842). Caaró, p. São Luiz, in rupestribus dumetosis, com frutos, 1. Arnetzen s.n., 10.X.1933 (PACA 1233).

Caçapava do Sul, Pedra do Segredo, com flores, madeira coletada, J. N. C. Marchiori 245, 14.I.1986 (HDCF 2197); Passo do Camaquã, CBC, A. A. Filho \& R. Cauduro s.n., 9.XII, 1989 (SMDB 2929). Dom Pedrito, Faz. da Toca, junto ao rio Tacuarembó-Chico, em borda de mata ciliar, com frutos, J. Mauhs \& M. S. Marchioretto s.n., 18.XI.2003 (PACA 87633). Encruzilhada do Sul, Faz. prox. ao Passo do Marinheiro, arbusto em campo, estéril, N. R. Bastos 141 \& S. Diesel s.n., 18.IV.1991 (PACA 70743); Espumoso, Vila São Jorge, material com flores, D. Vogel s.n., 29.VIII.1993 (SMDB 4802). Jari, p. Tupanciretã, in campestribus dumetosis, estéril, B. Rambo s.n., 26.I.1942 (PACA 9379). Lavras do Sul, Faz. dos Ferreira, em campo com afloramento rochoso, muito freqüente, com flores e frutos, N. R. Bastos 405, 7.XII.1993 (PACA 86872). Pedras Altas, Potreiro da Capororoca, com flores, madeira coletada, J. N. C. Marchiori s.n., 20.VII.1985 (HDCF 1779). Porto Alegre, in campestribus dumetosis, fr. novos, B. Rambo s.n., 1943 (PACA 11117). Pelotas, Instituto Agronômico do Sul, recém frutificado, Irmão A. Egydio 27, 28.I.1950 (PEL s.n.); ibidem, material vegetativo, A. Bertels 48, 17.VI.1950 (PEL s.n.); ibidem, borda de mato, material florido, C. Oliveira 43, 23.IX.1958 (PEL s.n.). Piratini, ca. de 2 km em direção à BR-293, subarbusto ca. $0,6 \mathrm{~m}$, em campo alto, frutos imaturos, verdes, J. A. Jarenkow 3594, 22.X.1997 (PEL 18.354). Quaraí, Faz. do Jarau, in rupestribus dumetosis, estéril, B. Rambo s.n., I.1945 (PACA 26307). Santana da Boa Vista, Cerro do Diogo, arbusto ca. 1,3 m, borda de mata à beira da BR-392, flores brancas, aromáticas, M. Sobral \& J. A. Jarenkow 7990, X.1995 (PEL 14.853). Santana do Livramento, estrada p. Quaraí, perto do arroio Caty, na margem, solo pedregoso, inundável, estéril, J. Mauhs s.n., 17.XI.2003 (PACA 87635). Santa Maria, Passo do Arenal, erva 03-0,5 m de altura, com flores, R. Beltrão s.n., 15.IX.1955 (SMDB 810); Barragem de Val de Serra, com frutos, O. Vargas s.n., (SMDB 2180); Val de Serra, campo, arbusto $1 \mathrm{~m}$ altura, raro, com flores, A. A. Filho s.n., 26.VIII. 1987 (SMDB 2688). São Gabriel, Faz. Santa Cecília, in rupestribus dumetosis, estéril, B. Rambo, s.n., I. 1944 (PACA 25772). São Lourenço do Sul, Faz. Crisanto Soares, arbustiva herba in campo, estéril, A. Sehnem s.n., 10.XII. 1965 (PACA 81536). Santiago,
Rincão dos Cardoso, campo de solo rochoso, divide espaço com mio-mio, caraguatá e algumas espécies de capim, flores brancas, imaturas, cheiro adocicado, Ionara F. C. \& Sandro G., s.n., 5.VIII.1999 (SMDB 9513). Uruguaiana, Imbaá, material estéril, S. J. Longhi 761, 29.XII.1986 (HDCF 2582); Touro Passo, material com flores rosadas, S. J. Longhi 871, 30.VIII.1987 (HDCF 2699).

A descrição botânica foi realizada mediante análise do material acima relacionado e da observação de indivíduos a campo. No exame das estruturas, usou-se lupa, régua de precisão $(0,5$ mm) e papel milimetrado; a terminologia baseouse em Radford et alii (1974). As informações relativas ao porte, fenologia, consistência e coloração de peças morfológicas valeram-se de informações constantes nas etiquetas de exsicatas e em observações feitas a campo; para os demais aspectos, buscou-se referências da literatura.

Para a descrição anatômica da madeira, foram preparadas lâminas de cortes anatômicos e de macerado.

De cada uma das amostras de madeira foram preparados três corpos-de-prova, orientados para a obtenção de cortes anatômicos nos planos transversal, longitudinal radial e longitudinal tangencial. Os corpos-de-prova foram amolecidos por fervura em água e trabalhados em micrótomo de deslize, regulado para a obtenção de cortes anatômicos com espessura nominal de $20 \mu \mathrm{m}$. Os cortes foram coloridos com acridina-vermelha, crisoidina e azul-de-astra (Dujardin, 1964), desidratados em série alcoólica ascendente $(30 \%, 50 \%, 75 \%, 90 \%, 95 \%$, duas vezes álcool absoluto) e montados em lâminas permanentes, com Entellan.

Das amostras de madeira também se obteve um quarto corpo-de-prova, com vistas à maceração. Usou-se, neste caso, a técnica de Jeffrey (Burger \& Richter, 1991), sendo a pasta resultante tingida com solução aquosa de safranina $1 \%$. A desidratação e montagem de lâminas permanentes seguiram o anteriormente descrito, com a diferença de que a primeira dessas etapas foi desenvolvida sobre papel de filtro. 
A terminologia, número de medições e descrição da estrutura antômica seguiram as recomendações da Copant (1973). Para a determinação da percentagem dos diferentes tipos celulares, seguiu-se a metodologia recomendada por Marchiori (1980). Os valores quantitativos, apresentados na Tabela 1 , são resultantes de 30 medições por caráter, com exceção da percentagem dos tipos celulares e das classes de raio, para os quais foram realizadas 600 determinações ao acaso; a freqüência de poros $/ \mathrm{mm}^{2}$ foi obtida de forma indireta, a partir de quadrados com área conhecida, superpostos em fotomicrografia de seção transversal. As medições foram realizadas em microscópio Carl Zeiss, no Laboratório de Anatomia da Madeira da Universidade Federal de Santa Maria. As fotomicrografias foram tomadas em aparelho Carl Zeiss, no Laboratório de Anatomia da Madeira da Universidade Federal do Paraná. Os desenhos constantes na Figura 1, são obra de Leonardo Paz Deble, a quem os autores agradecem.

\section{DESCRIÇÃO BOTÂNICA}

Arbusto de 0,30 a 1,30 m de altura, densamente ramoso e espinhento, com poucas ou muitas folhas, até ocasionalmente sub-áfilo. Ramos decussados, cilíndricos, com gemas na parte inferior da axila e ramificados em quase todos os nós (Figura 1a); quando jovens, são verdes, finos, flexíveis, de aspecto rugoso e por vezes puberulentos; lenhosos e de casca superficialmente fissurada, nos antigos; os de última ordem, são curtos (até $4,5 \mathrm{~cm}$ de comprimento), espinescentes, de extremidade muito aguda, rígida, marrom, quase sempre uninodos, retos a ligeiramente curvos, ascendentes e não ramificados; nós marcados por escura linha transversal. Folhas diminutas, verdes, pecioladas, glabras ou com alguma pilosidade (principalmente no dorso), decussadas, solitárias, ocasionalmente aos pares ou em fascículos nos ramos jovens (Figura 1a'); limbo oblanceolado a estreitamente oblongo, às vezes estreito-elíptico, inteiro ou menos freqüentemente serreado na metade superior, de 3,5-11,5 mm de comprimento por 1,3-2,7 mm de largura; ápice mucronado, retuso, arredondado, até acuminado, freqüentemente recurvo, ao menos quando seco; base estreitamente cuneada, às vezes longa e estreitando-se gradualmente; nervuras hipódromas, salientes na face abaxial (Figura 1b). Pecíolos de 0,5-2,0 $\mathrm{mm}$ de comprimento. Estípulas interpeciolares unidas em torno dos nós, de cor marrom, geralmente pareadas, triangulares, com parte distal freqüentemente caduca, medindo até $2,5 \mathrm{~mm}$ de comprimento e pilosas, sobretudo na face ventral (Figura 1a'). Flores completas, perfeitas, tetrâmeras, raramente pentâmeras, de simetria radial (Figura 1c), numerosas, brancas, glabras, pediceladas, pequenas $(4,0-11,5 \mathrm{~mm}$ de comprimento por 1,8 4,0 $\mathrm{mm}$ de largura), axilares e solitárias, às vezes aos pares ou em fascículos de 3, dispostas geralmente em pequenos ramos jovens, folhosos, produzidos pelo meristema axilar, os quais, ocasionalmente, podem estar bastante contraídos e afilos (Figura 1a'). Pedicelos de 1,0-6,7 mm de comprimento (Figura 1a'). Cálice petalóide, carnoso, em tubo de largura mais ou menos uniforme e 1,5-4,2 $\mathrm{mm}$ de comprimento, com nervuras evidentes e um pouco salientes na parte externa, ao menos em material seco (Figura 1c). Lacínias deltóides, de 0,9-1,5 mm de comprimento e ápice caloso, com uma nervura longitudinal-ventral espessa. Pétalas geralmente côncavas a cuculadas, às vezes planas, de forma ovada, elíptica ou deltóide; base curtounguiculada; ápice inteiro, acuminado (Figura 1e), em alternância e menores do que as sépalas (com metade a quase $2 / 3$ de sua altura), inseridas na extremidade do tubo, pouco evidentes. Disco nectarífero carnoso, espesso, glabro, hemisférico, localizado na base do tubo, adnato à metade inferior do ovário, mas com uma porção livre e elevada ao seu redor, horizontalmente ondulada, de bordo inteiro (Figura 1d). Estames opostos às pétalas, livres do disco; filetes laminares, ao menos em material seco, aderentes ao tubo em quase toda sua extensão, exceto na parte distal, que é livre; anteras 


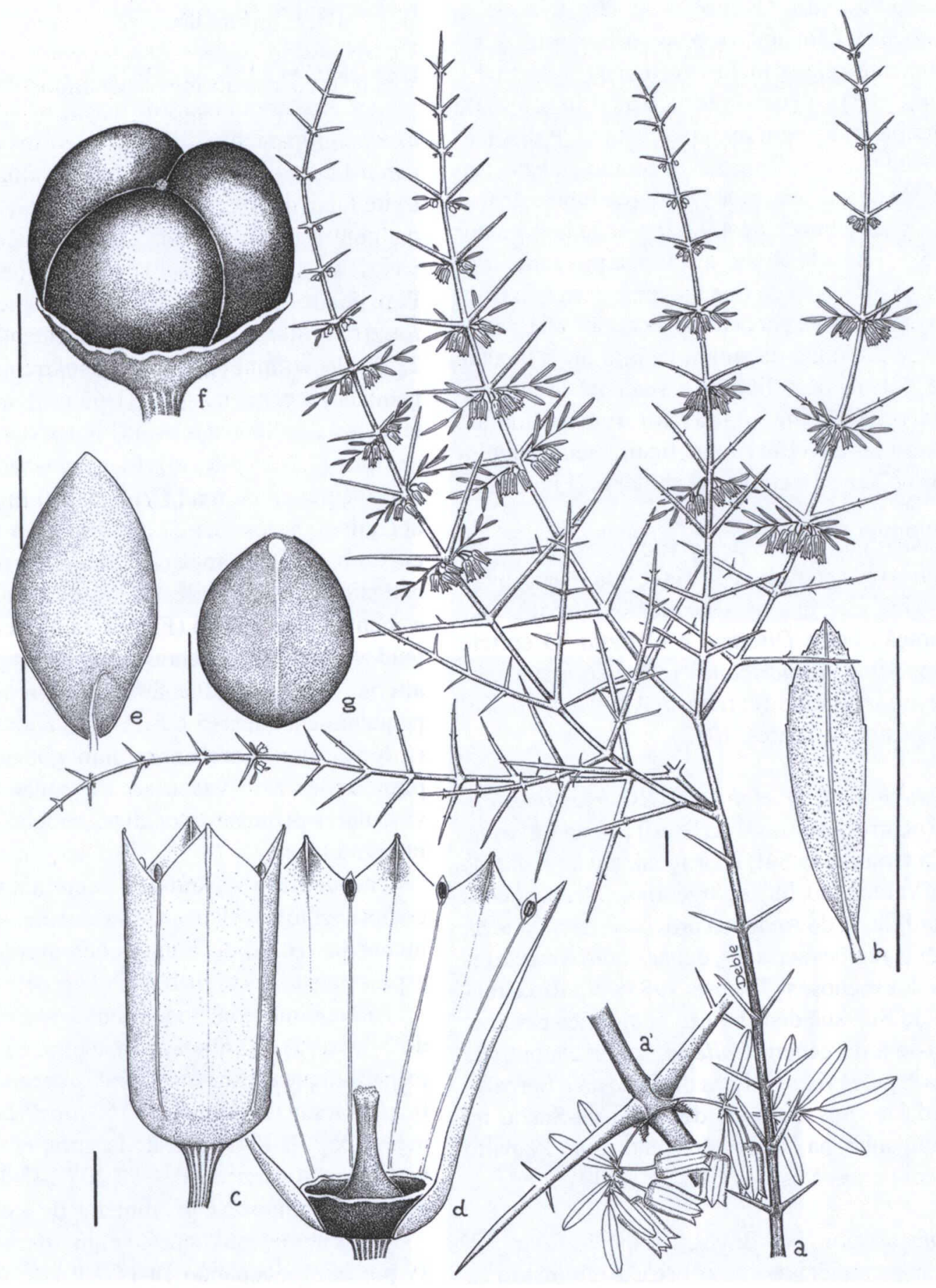

FIGURA 1. Ramo florido de Discaria americana (a). Detalhe de ramo (a'). Folha (b). Flor (c). Flor, com detalhe do disco (d). Pétala (e). Fruto (f). Semente (g). 
dorsifixas, rimosas e, com freqüência, ligeiramente rostradas. Ovário semi-ínfero, tricarpelar, trilocular, com um óvulo por lóculo; estilete geralmente longo e incluso; estigma trilobado ( $\mathrm{Fi}$ gura 1d). Fruto seco, do tipo cápsula anomalicida, com textura crustácea e distintamente tricoco (Figura 1f), envolto na base, antes da deiscência, pelos restos do tubo e do disco; glabro, mede de 4,0-6,0 $\mathrm{mm}$ de largura por 3,5-4,5 mm de altura; os mericarpos tornam-se livres entre si e da fina parede externa do fruto na maturidade, por ocasião da deiscência, abrindo-se ao longo da sutura ventral até a metade da dorsal, para liberar a semente. Sementes marrons, acinzentadas ou avermelhadas, obovadas em vista lateral, ligeiramente angulosas no ventre e convexas no dorso (Figura 1g).

Etimologia: De origem grega (diskos), o nome genérico remete ao disco da flor, peça morfológica que fornece elementos para a separação entre Discaria e Colletia. O epíteto específico (americana) refere-se à sua área de ocorrência, restrita à América do Sul (Johnston \& Soares, 1972).

Distribuição \& Habitat: Discaria america$n a$ ocorre desde o sul do Brasil (Santa Catarina, Rio Grande do Sul) e Uruguai, até a península de Valdez, no litoral argentino, alcançando a Cordilheira do Andes na província de Mendoza; habita regiões serranas, dunas, morros calcários e solos rochosos (Tortosa, 1983). No Rio Grande do Sul, sua distribuição geográfica assemelha-se à do gênero Colletia, sendo encontrada nas regiões fisiográficas da Encosta e Serra do Sudeste, nos Campos de Cima-da-Serra, na Campanha, na Depressão Central, no Planalto Médio e nas Missões (Bastos, 1999).

Comentários: No Brasil, a espécie é vulgarmente conhecida como brusca (Johnston \& Soares, 1972), quina-do-campo, quina-do-brasil e quina-do-rio-grande (Correa, 1984); na Argentina, como brusquilla, coronillo-del-campo e tola (Tortosa, 1995); e como quina-del-campo, no Uruguai (Lombardo, 1982). Floresce de agosto a dezembro (Bastos, 1999).

\section{DESCRIÇÃO DA MADEIRA}

Anéis de crescimento distintos, marcados por nítido agrupamento diagonal de vasos (padrão dendrítico) no lenho tardio, que termina em estreita faixa de fibras de diâmetro radial reduzido, contrastando com uma linha tangencial de vasos, no início do anel seguinte (Figura 2a). Porosidade difusa. Poros extremamente numerosos (325-485-625/ $\left.\mathrm{mm}^{2}\right)$, representando 8-16$22 \%$ do volume da madeira; extremamente pequenos a pequenos (15-31-63 $\mu \mathrm{m})$, apresentam seção poligonal a oval (Figura 2b) e paredes finas $(1,2-2,8-3,8 \mu \mathrm{m})$. Elementos vasculares muito curtos a curtos (170-273-330 $\mu \mathrm{m})$, com apêndices curtos (7,5-31-118 $\mu \mathrm{m})$, em uma ou em ambas as extremidades. Placas de perfuração simples (Figura 2c,3a). Vasos com espessamentos espiralados (Figura 3a,b), sem conteúdos. Pontoado intervascular em disposição alterna; pontoações de forma oval a circular, pequenas a médias (5-6,5-11 $\mu \mathrm{m})$, com abertura lenticular, horizontal, não guarnecida; pontoações raio-vasculares e parênquimovasculares pequenas a médias, semelhantes às intervasculares.

Traqueídeos vasculares semelhantes em comprimento aos elementos vasculares, e igualmente providos de pontoações areoladas e espessamentos espiralados na parede.

Parênquima axial pouco abundante, ocupando $2-7,8-11 \%$ do volume da madeira, em arranjo paratraqueal escasso. Células parenquimáticas retangulares, de 35-65-150 $\mu \mathrm{m}$ de comprimento por 10-13-18 $\mu \mathrm{m}$ de largura, em séries verticais não estratificadas, de 107-243-350 $\mu \mathrm{m}$ de altura, compostas, geralmente, de 4 células.

Raios numerosos a muito numerosos (7-1319 por $\mathrm{mm}$ ), ocupando $10-14-18 \%$ do volume da madeira. Tecido radial fracamente heterogêneo, composto de células quadradas, com uma faixa marginal de células mais altas (fracamente eretas). Raios unisseriados abundantes (26- 

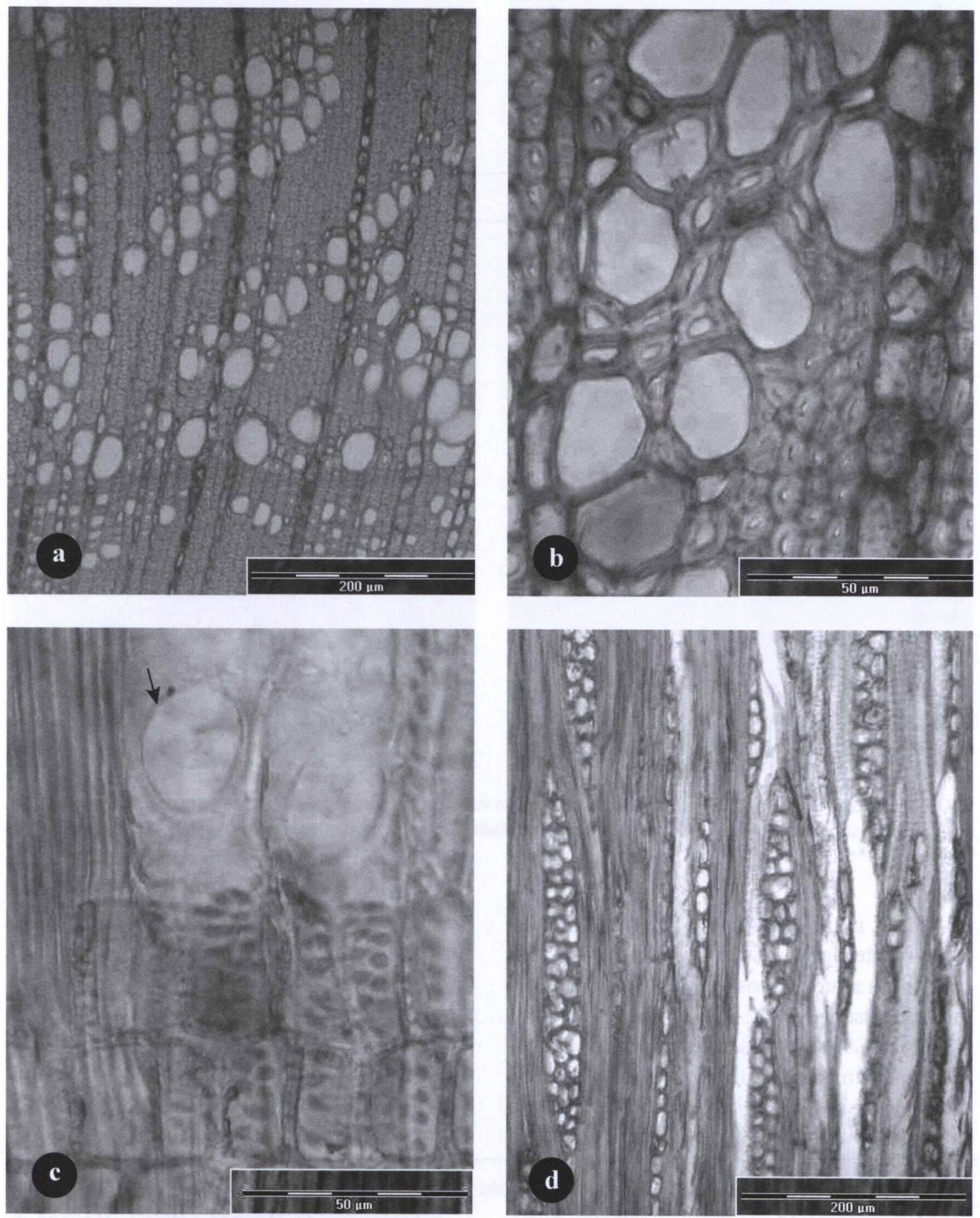

FIGURA 2 - Aspectos anatômicos da madeira de Discaria americana. Seção transversal, mostrando anéis de crescimento distintos, porosidade dendrítica e fibras de paredes espessas (a). Os mesmos detalhes, com maior aumento (b). Seção longitudinal radial, destacando células radiais quadradas e eretas, dois vasos com placas de perfuração simples e o pontoado raio-vascular (c). Raios de 1-4 células de largura, em seção longitudinal tangencial (d). 

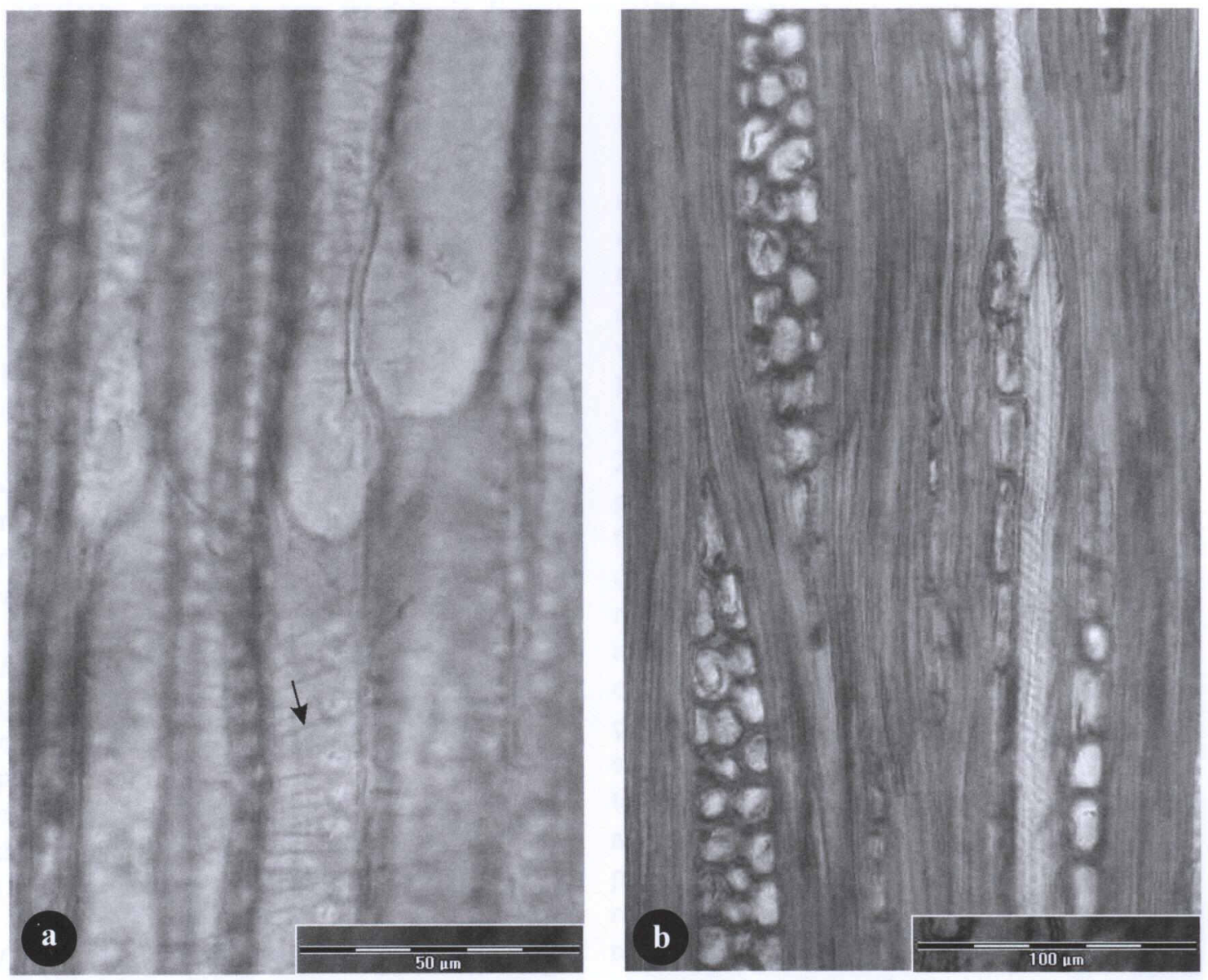

FIGURA 3. Seção longitudinal radial da madeira, destacando vasos com espessamentos espiralados na parede (seta) e placas de perfuração simples (a). Vasos com espessamentos espiralados e raios, em seção longitudinal tangencial (b).

$37-45 \%)$, muito baixos (75-186-490 $\mu \mathrm{m})$, extremamente finos (7,5-13-25 $\mu \mathrm{m})$, com 1-7-18 células em altura. Raios multisseriados, em sua maioria bisseriados (22-31,7-43\%), trisseriados (19-25,7-36 \%) e escassos tetrasseriados (1-5,6$11 \%)$; muito baixos a medianos (160-405-763 $\mu \mathrm{m})$, com 6-19-36 células de altura, e de muito finos a estreitos (17,5-32,5-72,5 $\mu \mathrm{m}), \operatorname{com} 2$ a 4 células de largura (Figura 2d). Células esclerosadas, latericuliformes, mucilaginosas, envolventes e oleíferas, ausentes. Raios de relacionamento normal; raios agregados e fusionados, ausentes.

Tecido fibroso proeminente, ocupando 51-62$67 \%$ do volume da madeira, composto de fi- bras libriformes extremamente curtas a muito curtas $(470-645-810 \mu \mathrm{m})$, de paredes espessas $(2,5-3,6-5,0 \mu \mathrm{m})$ e com pontoações simples diminutas. Fibras gelatinosas, freqüentes.

Canais secretores, tubos laticíferos e taniníferos, líber incluso, estratificação e cristais, ausentes. Máculas medulares, ocasionais.

\section{ANÁLISE DA ESTRUTURA ANATÔMICA}

A descrição anatômica descrita coincide com as referências de Record (1939), Record \& Hess (1949) e Metcalfe \& Chalk (1972) para a família Rhamnaceae e gênero Discaria: anéis de crescimento distintos; poros muito numerosos, pequenos a diminutos e em arranjo dendrítico 
TABELA 1: Dados quantitativos da madeira.

\begin{tabular}{|c|c|c|c|c|c|}
\hline$n^{\circ}$ & Característica anatômica & mín. & média & máx. & $\mathbf{s}$ \\
\hline 1 & Fração de poros (\%) & 8,0 & 16,0 & 22,0 & 4,60 \\
\hline 2 & Freqüência de poros (poros $/ \mathrm{mm}^{2}$ ) & 325 & 485 & 625 & 88,30 \\
\hline 3 & $\varnothing$ total de poros $(\mu \mathrm{m})$ & 15,0 & 31,0 & 63,0 & 9,80 \\
\hline 4 & $\varnothing$ do lume de poros $(\mu \mathrm{m})$ & 12,5 & 25,5 & 55 & 9,30 \\
\hline 5 & Espessura da parede de poros $(\mu \mathrm{m})$ & 1,2 & 2,8 & 3,8 & 0,68 \\
\hline 6 & Comprimento de elementos vasculares $(\mu \mathrm{m})$ & 170 & 273 & 330 & 39,00 \\
\hline 7 & Comprimento de apêndices $(\mu \mathrm{m})$ & 7,5 & 31 & 118 & 22,10 \\
\hline 8 & $\varnothing$ pontoações intervasculares $(\mu \mathrm{m})$ & 5,0 & 6,5 & 11 & 1,20 \\
\hline 9 & $\emptyset$ pontoações raio-vasculares $(\mu \mathrm{m})$ & 4,0 & 5,9 & 12 & 1,70 \\
\hline 10 & Ø pontoações parênquimo-vasculares $(\mu \mathrm{m})$ & 4,0 & 5,3 & 9,0 & 1,10 \\
\hline 11 & Fração de parênquima axial (\%) & 2,0 & 7,8 & 11 & 2,80 \\
\hline 12 & Altura das séries de parênq. axial $(\mu \mathrm{m})$ & 107 & 243 & 350 & 45,50 \\
\hline 13 & Altura das séries de parênq. axial (células) & 2 & 4 & 6 & 0,60 \\
\hline 14 & Altura das células de parênquima axial $(\mu \mathrm{m})$ & 35 & 65 & 150 & 17,70 \\
\hline 15 & Largura das células de parênquima axial $(\mu \mathrm{m})$ & 10 & 13 & 18 & 1,90 \\
\hline 16 & Fração de raios (\%) & 10 & 14 & 18 & 2,80 \\
\hline 17 & Freqüência de raios (raios/mm) & 7 & 13 & 19 & 3,33 \\
\hline 18 & Fração de raios unisseriados (\%) & 26 & 37 & 45 & 5,40 \\
\hline 19 & Altura de raios unisseriados $(\mu \mathrm{m})$ & 75 & 186 & 490 & 90,20 \\
\hline 20 & Altura de raios unisseriados (células) & 1 & 7 & 18 & 3,90 \\
\hline 21 & Largura de raios unisseriados $(\mu \mathrm{m})$ & 7,5 & 13 & 25 & 3,30 \\
\hline 22 & Altura de raios multisseriados $(\mu \mathrm{m})$ & 160 & 405 & 762 & 161,30 \\
\hline 23 & Altura de raios multisseriados (células) & 6 & 19 & 36 & 7,60 \\
\hline 24 & Largura de raios multisseriados $(\mu \mathrm{m})$ & 17,5 & 32,3 & 72,5 & 10,60 \\
\hline 25 & Largura de raios multisseriados (células) & 2 & 3 & 4 & 0,60 \\
\hline 26 & Fração de raios bisseriados (\%) & 22 & 31,7 & 43 & 7,30 \\
\hline 27 & Fração de raios trisserriados (\%) & 19 & 25,7 & 36 & 4,90 \\
\hline 28 & Fração de raios tetrasseriados (\%) & 1,0 & 5,6 & 11,0 & 2,70 \\
\hline 29 & Fração de fibras $(\%)$ & 51 & 62 & 67 & 4,90 \\
\hline 30 & Comprimento de fibras $(\mu \mathrm{m})$ & 470 & 645 & 810 & 89,80 \\
\hline 31 & $\varnothing$ de fibras $(\mu \mathrm{m})$ & 10,0 & 12,6 & 17,5 & 2,02 \\
\hline 32 & $\varnothing$ lúmen de fibras $(\mu \mathrm{m})$ & 2,5 & 5,4 & 10,0 & 1,48 \\
\hline 33 & Espessura parede de fibras $(\mu \mathrm{m})$ & 2,5 & 3,6 & 5,0 & 0,71 \\
\hline
\end{tabular}

mín $=$ valor mínimo; máx $=$ valor máximo; $\mathrm{s}=$ desvio padrão; $\mu \mathrm{m}=$ micrômetros; $\varnothing=$ diâmetro . 
ou diagonal; elementos vasculares muito curtos a curtos, com placas de perfuração simples e espessamentos espiralados na parede; traqueídeos vasculares presentes, também providos de espessamentos espiralados na parede; raios heterogêneos, com 1-4 células de largura; parênquima paratraqueal escasso; e fibras de paredes espessas, com pontoações diminutas.

Com relação às referências bibliográficas, cabe salientar, todavia, que o material em estudo não apresenta a típica porosidade em anel; não havendo variação sensível no diâmetro dos vasos, o início do anel é marcado por uma linha tangencial de poros que contrasta com o arranjo dendrítico, muito característico no lenho tardio.

Considerando as demais espécies do gênero, a espécie em estudo apresenta raios mais finos, não havendo raios com mais de 4 células de largura.

A ocorrência de poros extremamente pequenos, numerosos e em arranjo dendrítico (ou diagonal) é freqüente em arbustos de locais secos, segundo Carlquist (1966), como é o caso da espécie em estudo. A ocorrência de elementos vasculares muito curtos e com espessamentos espiralados na parede também pode ser interpretado como estratégia ecológica, pois aumenta a superfície interna dos mesmos e, portanto, a sua capilaridade (Carlquist, 1966).

Os traqueídeos vasculares com espessamentos espiralados, observados em Discaria americana, constituem caráter freqüente nas Ramnáceas com vasos em arranjo diagonal ou dendrítico, segundo Metcalfe \& Chalk (1972).

\section{BIBLIOGRAFIA}

Barroso, G. M. Sistemática de Angiospermas do Brasil. Viçosa: UFV, 1984. v. 2. p. 237-239.

Bastos, N. R., Morais, D. A família Rhamnaceae R. Br. no RS: Estudo taxonômico dos gêneros Discaria Hooker e Colletia Commerson ex Jussieu. Pesquisas, Série Botânica, São Leopoldo, n. 49, p. 121-142, 1999.
Burger, L. M., Richter, H. G. Anatomia da Madeira. São Paulo: Nobel, 1991. 154 p.

Bustamante, L. E. N. Flora de la cuenca de Santiago de Chile. Santiago: Ediciones da la Universidad de Chile, 1976. v. 2. 559 p.

Copant. Comissão Panamericana de Normas Técnicas. Descrição macroscópica, microscópica e geral da madeira - esquema I de recomendação. Colômbia, 1973. 19 p. (COPANT 30).

Correa, M. P. Dicionário das plantas úteis do Brasil e das exóticas cultivadas. Rio de Janeiro: Ministério da Agricultura, Instituto Brasileiro de Desenvolvimento Florestal, 1984. v. 5. p.568.

Dujardin, E. P. Eine neue Holz-Zellulosenfaerbung. Mikrokosmos, n. 53, p. 94, 1964.

Hurrell, J. A., Bazzano, H. B. Arbustos 1. Nativos y exóticos. Buenos Aires: L.O.L.A., 2003. 264 p.

Johnston, M. C., Soares, M. A. de F. Ramnáceas. In: Reitz, P. R. Flora Ilustrada Catarinense. Itajaí: Herbário Barbosa Rodrigues, 1972. 50 p.

Lombardo, A. Flora Montevidensis. Montevideo: Intendencia Municipal, 1982. v. 1, p. 316 p.

Marchiori, J. N. C. Estudo anatômico do xilema secundário de algumas espécies dos gêneros Acacia e Mimosa, nativas no Estado do Rio Grande do Sul. Curitiba: UFPR, 1980. 186 p. Dissertação (Mestrado em Engenharia Florestal) Universidade Federal do Paraná.

Metcalfe, C. R., Chalk. L. Anatomy of the Dicotyledons. Oxford: Clarendon Press, 1972. $1500 \mathrm{p}$.

Radford, A.E., Dickson, W. C., Massey, J. R., Bell, C. R. Vascular Plant Systematics. New York: Harper \& Row, 1974. 891p.

Record, S. J. American woods of the family Rhamnaceae. Tropical Woods, n. 58, p. 6-24, 1939.

Record, S. J., Hess, R. W. Timbers of the New World. New Haven: Yale University Press, 1949. 640 p.

Schultz, A. R. H. Introdução à Botânica Sistemática. Porto Alegre: Editora UFRGS, 1984. v. 2.414 p.

Tortosa, R. D. El género Discaria (Rhamnaceae). Boletín de la Sociedad Argentina de Botánica, v. 22, n. 1-4, p. 331-335, 1983.

Tortosa, R. D. Flora fanerogámica argentina: Rhamnaceae. Córdoba: Programa Proflora (Conicet), Museo Botánico, 1995. fasc. 9.18 p. 